\title{
Risk-Return Dynamics of the Chinese Stock Market: A Comparison between A, B and H Shares
}

\author{
Sunil K. Mohanty ${ }^{1}$, Mohan Nandha ${ }^{2}$, Abdulal Abu Khashabah ${ }^{3} \&$ Abdullah Asiri ${ }^{3}$ \\ ${ }^{1}$ Department of Finance, Brooklyn College, City University of New York, Brooklyn, NY, USA \\ ${ }^{2}$ Department of Banking and Finance, Monash University, Australia \\ ${ }^{3}$ Faculty of Economics and Administration, Department of Accounting, King Abdulaziz University, Jeddah, \\ Saudi Arabia \\ Correspondence: Sunil K. Mohanty, Department of Finance, Brooklyn College, City University of New York, \\ Brooklyn, NY, USA. E-mail: skmohanty@ brooklyn.cuny.edu
}

Received: June 14, 2015

Accepted: July 13, 2015

Online Published: July 25, 2015

doi:10.5539/ibr.v8n8p79

URL: http://dx.doi.org/10.5539/ibr.v8n8p79

\begin{abstract}
This study compares the risk-return characteristics of the Chinese A shares with that of B and H shares over the period from January 1995 to June 2012. On average, B and H shares offer a better risk-adjusted return irrespective of whether the returns are measured in the Chinese Yuan (domestic perspective) or in the US dollar (foreign perspective) terms. However, a 'timeline' analysis indicates that the relative advantage arising from investment in B or H shares may be nearing the end. This finding appears to be a consequence of investment schemes which allow domestic and foreign investors to cross each other's territories after opening up of the Chinese market to foreign investors. Second, there is some evidence of exchange rate advantage for foreign investors, even though it is negligible. The results of our study suggest that any additional benefit generated by slight (average annual) appreciation of Yuan against the dollar is offset by an increase in volatility of returns measured in the US dollar.
\end{abstract}

Keywords: Chinese stock market, A-shares, B-shares, H-shares, the Sharpe Ratio

\section{Introduction}

Record economic growth and enormous market size of China have encouraged many multinational corporations and institutional investors to invest billions of dollars in China directly and indirectly. These foreign investments have generated millions of jobs for the Chinese workers. Many workers in resource rich countries like Australia, Brazil, Canada and South Africa have their jobs linked to the Chinese market as their employers' depend on Chinese demand for foreign resources. Other people have their wealth and retirement tied to the Chinese stock market through investment in Chinese stocks. As such the international community and the Chinese policymakers are always keen to enhance their understanding about the different aspects of the Chinese stock market. Furthermore, there are some market mechanisms which make the Chinese market relatively special from a research perspective. For example, Chinese stocks (Note 1) have various classifications such as A shares, B shares and $\mathrm{H}$ shares, and trading of these shares is subject to several restrictions related to foreign as well as domestic investors. In addition, trading occurs in different currencies namely, the Chinese Yuan (CNY), the US dollar (USD) and the Hong Kong dollar (HKD). Specifically, A shares listed on the mainland stock exchanges are priced in the Chinese Yuan and are mainly for investment by domestic investors. On the other hand, B shares were originally aimed at the foreign investors but since February, 2001, domestic investors have been allowed to invest in the B shares (Note 2). H shares listed in the Hong Kong stock exchange are priced in the Hong Kong dollar and mainly traded by foreign investors. However, domestic investors need to have lawful foreign currency funds. Interestingly, different classes of shares issued by the same company offer identical ownership and dividend rights, but price differences between the share classes have been reported as significant. In an article aimed at practitioners, Guo (2007) reported that on an average basis, $\mathrm{H}$ shares traded at a $35 \%$ discount and B shares traded at a $36 \%$ discount to A shares. Guo argues that the primary reasons for these price differences may be due to restrictions on capital flows and different investor bases for different share classes.

This study aims to conduct a detailed analysis of the risk-return characteristics of Chinese A, B and H shares 
from domestic and foreign investors' perspectives. B and $\mathrm{H}$ shares were originally aimed at foreign investors, and both classes have experienced almost similar discounts (at least for some initial period as reported by Guo, 2007) with respect to A shares. For the purpose of our study. B and H shares are considered one group and its performances are compared with that of A shares. Furthermore, both B \& H shares are aimed at attracting foreign currency capital. Another reason for classifying B \& H shares into same group is the availability of data as explained under the data section (section 3.3). Specifically, this study attempts to address the following research questions:

a. Do the Chinese A share versus $B$ and $H$ share prices reflect similar risk adjusted return? Considering that a fair comparison can be made only if returns are measured in the same currency, this question is examined both from the domestic (Yuan) and foreign (US dollar) investors view point.

b. Does the risk adjusted return for the domestic and foreign investors differ?

Exchange rates play an important role in determining the return and risk from foreign investments. This question is aimed at isolating the impact of the exchange rate (between the Chinese Yuan and the US dollar) in relation to A shares (domestic) versus $\mathrm{B}$ and $\mathrm{H}$ shares (foreign).

c. Have the relaxation of restrictions on shares trading (by domestic and foreign investors) impacted the risk-return characteristics of different share classes?

It is worth noting that Chinese regulatory authorities have introduced several schemes (as described under section 2.1) allowing cross investments in different share classes by domestic and foreign investors. These measures can be expected to reduce the pricing gaps (between different share prices) from early stages of the opening up Chinese market to more recent periods.

The rest of the paper is organized as follows: Section 2 provides an overview of the Chinese stock market and reviews the related literature. Section 3 describes the empirical framework and the data. Section 4 discusses appropriate measures of the Sharpe ratio and the development of several testable hypotheses. Section 5 presents empirical results and discusses implications of the study. Finally, Section 6 provides the summary and conclusions of the study.

\section{The Chinese Stock Market and Related Literature}

\subsection{An Overview of the Chinese Stock Market}

The Chinese securities market is regulated and supervised by the China Securities Regulatory Commission (CSRC) which is under the direct control of the State Council (Chinese cabinet). The Chinese securities market is composed of two stock exchanges (Shanghai Stock Exchange and Shenzhen Stock Exchange), three commodity futures exchanges and one financial futures exchange. The securities listed on these exchanges include stocks, bonds, investment funds, warrants, index futures and commodity futures. The stocks issued by the People's Republic of China (PRC) incorporated companies are divided into A, B, H shares.

In general, all categories of stock shares have the same voting rights and cash flow rights (e.g., they are entitled to the same dividends). They differ only in the types of owners. The state and the legal person stock shares represent the government ownership, while the individual stock shares (domestic and foreign) represent private ownership. For all categories of stockholders, the board of directors is the governance mechanism, and it adopts a two-tier structure, i.e., the upper and lower boards. The upper board is composed of non-executive directors for supervisory purpose, while the lower board is made up of executive directors for day-to-day management.

A shares are stocks of PRC incorporated companies listed on the Shenzhen and Shanghai stock exchanges. These shares are priced in Chinese Yuan (or Renminbi) and are primarily for Chinese mainland investors. Foreign investors, including investors from Hong Kong, Macau and Taiwan, are not allowed to buy A shares. $B$ shares, also known as 'foreign invested shares listed in China', are the stocks of PRC incorporated companies listed on Shenzhen and Shanghai stock exchanges, but the trading currencies for B shares are different. Though B shares are denominated in Renminbi they are subscribed and traded in foreign currencies. Specifically, the B shares listed on the Shanghai Stock Exchange (SSE) are traded in US dollars and those listed on the Shenzhen stock exchange (SZSE) are traded in Hong Kong dollars. The first issue of B shares was listed on SSE in February 1992 by a company named Shanghai Vacuum Electron Devices. These shares were denominated in Renminbi (RMB) at par of RMB100 and issued to foreign investors for US $\$ 18.8$ each (Note 3). B shares were originally meant for foreign investors, but later the domestic investors have been allowed to trade B shares. As indicated by the numbers in Table 1, B shares have not become popular among the investors and the number of B stocks is relatively small and has been declining over the last decade. 
Table 1. A snapshot of the China's stock market (2000-2012)

\begin{tabular}{|c|c|c|c|c|c|c|c|c|c|c|c|c|c|}
\hline Item & 2000 & 2001 & 2002 & 2003 & 2004 & 2005 & 2006 & 2007 & 2008 & 2009 & 2010 & 2011 & 2012 \\
\hline No. of listed companies (A \& B shares) & 1088 & 1160 & 1224 & 1287 & 1377 & 1381 & 1434 & 1550 & 1625 & 1718 & 2063 & 2342 & na \\
\hline No. of listed companies (B shares) & 114 & 112 & 111 & 111 & 110 & 109 & 109 & 109 & 109 & 108 & 108 & 108 & na \\
\hline No. of foreign listed companies ( $\mathrm{H}$ shares) & 52 & 60 & 75 & 93 & 111 & 122 & 143 & 148 & 153 & 159 & 165 & 171 & na \\
\hline Total outstanding shares $(\mathrm{bln})^{*}$ & 379.2 & 521.8 & 587.5 & 642.8 & 714.9 & 763 & 1492.6 & 2241.7 & 2452.3 & 2616.3 & 3318.4 & 3609.6 & na \\
\hline Free float (bln shares)* & 135.4 & 181.3 & 203.7 & 227 & 257.7 & 291.5 & 344.5 & 1033.2 & 1257.9 & 1976 & 2564.2 & 2885 & na \\
\hline Total market cap (RMB, bln)* & 4809.1 & 4352.2 & 3832.9 & 4245.8 & 3705.6 & 3243 & 8940.4 & 32714.1 & 12136.6 & 24394 & 26542.3 & 21475.9 & na \\
\hline Free float market cap $(\mathrm{RMB}, \mathrm{bln})^{*}$ & 1608.8 & 1446.3 & 1284.5 & 1317.9 & 1168.9 & 1063.1 & 2500.4 & 9306.4 & 4521.4 & 15125.9 & 19311 & 16492.1 & na \\
\hline Stock turnover (RMB, bln)* & 6082.7 & 3830.5 & 2799 & 3211.5 & 4233.4 & 3166.3 & 9046.9 & 46055.6 & 26711.3 & 53598.7 & 54563.4 & 42164.7 & na \\
\hline SSE composite index (closing) & 2073.48 & 1645.97 & 1357.65 & 1497.04 & 1266.50 & 1161.06 & 2675.47 & 5261.56 & 1820.81 & 3277.14 & 2808.08 & 2199.42 & na \\
\hline No. of securities investment funds (SIF) & 34 & 51 & 71 & 95 & 161 & 218 & 307 & 346 & 439 & 557 & 704 & 915 & na \\
\hline Turnover of SIFs (RMB, bln)* & 246.6 & 256.2 & 116.7 & 68.3 & 72.9 & 77.3 & 187.9 & 862 & 583.1 & 1025 & 899.6 & 636.6 & na \\
\hline
\end{tabular}

Note. a. Data sourced from various reports available on the websites of SSE (Shanghai Stock Exchange), SZSE (Shenzhen Stock Exchange) and CSRC (China Securities Regulatory Commission).

b. *Data relates to both A and B shares where 'bln' is a short expression for billion.

$H$ shares known as 'foreign-invested shares listed overseas' are the stocks of PRC incorporated companies listed on stock exchanges outside the China mainland territory. Most of the $\mathrm{H}$ shares are listed on the Hong Kong stock exchange and traded in Hong Kong dollars. These shares are mainly for the foreign investors. H shares were first issued by Tsingtao Brewery Company Limited in June 1993. Since the opening up of the Chinese market to foreign investors in 1992, the Chinese authorities have implemented various schemes which allow domestic and foreign investors to cross the initial described boundaries and cross investment in different types of Chinese shares. Such changes are expected to impact the risk-return dynamics of the Chinese shares in the long run. Thus, it is important to have some idea about the relevant Chinese investment schemes described as follows:

\subsubsection{Opening of B Shares to Domestic Investors}

Initially the B shares market was intended to attract foreign capital. However, with the availability of alternatives such as $\mathrm{H}$-shares and red-chips, the significance of $\mathrm{B}$ shares declined. Thus, with a view to attract foreign currency capital from domestic investors, the Chinese authorities opened the B shares market to domestic investors in February 2001. It is worth noting that domestic investors need lawful funds of foreign currency for investment in B shares.

\subsubsection{Qualified Foreign Institutional Investors (QFIIs) Scheme}

Foreign investment in A shares was allowed in September 2006 through QFIIs scheme. For securing a QFII licence, an applicant needs to have good credit standing, sound financial condition and a minimum size of assets as required by the CSRC. At the end of 2011, there were 135 QFIIs subjected to a total investment quota of US\$ 21.64 billion. The total holdings of QFIIs accounted for 1.07\% of the combined free float capitalisation of A shares. Further details about QFIIs and their operational aspects are available in CSRC Decree No. 36 (Note 4).

\subsubsection{Qualified Domestic Institutional Investors (QDIIs) Scheme}

A QDII refers to a financial institution approved by the Chinese regulatory agencies and having excellent investment capabilities. The QDII scheme was launched in August 2006 as a transitional arrangement to enable overseas investment by domestic firms. QDIIs can raise funds in China for investment in overseas securities portfolios. Related administration measures were approved by the CSRC on April 30, 2007, and became effective from July 5, 2007 (CSRC Decree No. 46). As at the end of 2011, there were 42 QDIIs and 59 fund products approved for QDII investment (CSRC annual report, 2011).

\subsection{Related Literature}

Various studies have highlighted divergent characteristics of different types of Chinese shares. For example, in an earlier Chinese market study, Bailey (1994) indicates the Chinese B shares to be trading at a discount relative 
to A shares and argues that the existence of discounts on B shares represent a phenomenon inconsistent with the premiums observed in other Asian markets. Sun and Tong (2000) also report the B shares being priced at a discount relative to A shares and their evidence being contrary to what has been observed in other markets with similar segmented structure. The 2001 reform helped eliminate restrictions on B share ownership. Before the reform, B shares had been owned entirely by foreign accounts. The reform led to an inflow of domestic capital (in US \$ or HK\$) into the B-shares and $\mathrm{H}$-shares markets respectively.

The type of investor behavior may be due to the different characteristics of A, B and H-share markets such as the dominance of domestic individual investors in the A share market and the dominance of foreign institutional investors in the B and H-share market. Yeh et al. (2002) argue that where firms list separate shares for trading by domestic and foreign investors (e.g., A and B shares in China), the prices of the shares traded by foreign investors tends to be higher, but in China, the reverse tends to be true. In a study based on Chinese companies that issued both A and H shares, Wang and Jiang (2004) find that the A share and H share returns have different relations to their domestic markets (Shanghai/Shenzhen and Hong Kong respectively) as well as foreign markets. Further, they show that $\mathrm{H}$ shares trade at a significant discount relative to A shares. $\mathrm{Li}$ et al. (2006) explore the price discounts on $\mathrm{H}$ shares relative to A shares and suggest that the price differentials in the Chinese dual-listed $\mathrm{A}$ and $\mathrm{H}$ shares are mainly attributed to the deviation in the systemic risk premiums of their local markets. Further, they argue that the exchange rate change between the Hong Kong dollar and the Chinese Yuan does not have any significant effects on the price discounts of $\mathrm{H}$ shares.

The 2005-2006 reform undertaken by the Chinese government aimed at making the nontradable shares tradable. The reform helped remove significant market friction, leading to better incentive alignment between controlling and minority shareholders (e.g., Firth, Lin, \& Zou, 2010; Li, Wang, Cheung, \& Jiang, 2011; Chen, Jin, \& Yuan, 2011; Beltratti, Bortolotti, \& Caccavaio, 2012; Chen, Chen, Schipper, Xu, \& Xue, 2012; and Hou, Kuo, \& Lee, 2012). In addition, according to Green, Morris, and Tang (2010), the reform led to a positive impact on transparency. By the end of 2006, domestic investors accounted for about $88 \%$ of all B-share trading accounts (e.g., Bohl, Schuppli, \& Siklos, 2010; and Chen, Jiang, Li, \& Sim, 2010).

In general, studies relating to Chinese stocks appear to indicate that the A shares are being traded at premium relative to $\mathrm{B}$ and $\mathrm{H}$ shares. Most of these studies are focused on the return component and the risk part of investment decisions have not been given due consideration. However, some recent studies published in the domestic Chinese journals have attempted to address the risk aspects of the Chinese stock markets. For example, Johansson (2009) shows that both the Shanghai and Shenzhen stock markets have a low average systematic risk compared to the world market. Shum and Tang (2010) examine the risk-return characteristics of BRIC (Brazil, Russia, India and China) markets over the period January 2003 to July 2007. By using weekly stock market indices for BRIC countries, they show that China and Brazil have the largest Sharpe ratio. Further, they suggest that Chinese stock market is the only one of the BRIC markets which generates positive abnormal risk-adjusted returns. Their data set includes market indices for the Shanghai and Shenzhen stock exchanges but they do not differentiate between different Chinese share types. Overall, there appears to be no study which casts light on the risk-return dynamics of different types of Chinese shares.

\section{Empirical Framework and the Data}

\subsection{Risk-Return Relationship}

Earning a positive return is a fundamental motive behind investment decisions. A return is what one earns on an investment over some period and is usually expressed in annualised percentage terms. However, a return cannot be isolated from the risk (or uncertainty) associated with the underlying returns on the investment. Unlike returns, defining and measuring risk is a debatable issue, but for all empirical purposes (and widely used by the academic community), standard deviation of returns has been accepted as a good proxy of investment risk. As a fundamental investment rule, the greater the risk involved in an investment, the higher the return investors would require as compensation for bearing that risk. Thus, when comparing the performance of multiple investments, it is quite common to examine the returns with due consideration to the risk (standard deviation) of associated returns. Consequently, the literature has proposed various risk-return ratios which can be used for measuring and comparing performance of multiple investments. Such ratios include the Sharpe ratio, Treynor ratio, Jensen's measure and Sortino ratio. Though none of these ratios is considered perfect, but the Sharpe ratio is the most popular in use and has been selected for this study.

\subsection{The Sharpe Ratio}

The idea of the Sharpe ratio was originated by the Noble laureate William F. Sharpe as a measure of risk adjusted return (Sharpe, 1966 and 1994). The Sharpe ratio can be defined using an ex-anti or ex-post measure of returns. 
Considering the empirical nature of this study, the methodology in this study is focused around the ex-post the Sharpe ratio (SR) which is defined as the average excess return divided by the standard deviation of the underlying excess returns. In descriptive terms, a the Sharpe ratio represents the average amount of excess return for taking a unit of risk where risk is measured by the standard deviation of underlying excess returns. As such, the Sharpe ratio appears to be quite useful for comparing the performance of different assets. Though returns on treasury bonds are usually used as a proxy for risk-free return in reality risk-free return is more theory than a fact. As treasury bonds involve sovereign risk and yields on bonds fluctuate with market conditions, there appears to be no risk free return. Thus, following Sharpe (1994, p. 50), the SR in this study is defined as:

$$
S R=\frac{\bar{D}}{\sigma_{D}}
$$

where $\bar{D}$ is the average of the difference of returns $\mathrm{R}_{\mathrm{i}, \mathrm{t}}$ on an index ' $\mathrm{i}$ ' against a benchmark return (such as interest rate) $R_{b, t}$ over the period $t=1,2 \ldots . . \mathrm{T}$; and $\sigma_{D}$ is the standard deviation of differential returns. Symbolically,

$$
\bar{D}=\frac{1}{T} \sum_{t=1}^{T} D_{t} \text { and } \sigma_{D}=\left[\frac{\sum_{t=1}^{T}\left(D_{t}-\bar{D}\right)^{2}}{T-1}\right]^{1 / 2} \text { where } \mathrm{D}_{\mathrm{t}}=\mathrm{R}_{\mathrm{i}, \mathrm{t}}-\mathrm{R}_{\mathrm{b}, \mathrm{t}} \text { for } \mathrm{t}=1,2 \ldots \ldots \mathrm{T}
$$

As the study involves comparing the risk adjusted return across different data series, the Sharpe ratio can be appropriately manipulated to serve the purpose. In Sharpe's own words (Sharpe, 1994), "Properly used, it (the Sharpe ratio) can improve the process of managing investments".

\subsection{The Data}

For conducting an empirical analysis, the data is required for different types of Chinese share prices, benchmark interest rates for China and the US, and the exchange rate for the Chinese Yuan against the US dollar. All the data is available from the Thomson Reuters Datastream. Interestingly, Datastream has assigned a special status to the Chinese market in a sense that China is the only market in the world for which Datastream provides two sets of equity indices. One set of these equity indices relates to Chinese A shares and other set is for B and $\mathrm{H}$ shares (Note 5). Datastream claims that its equity indices are unique and advantageous in a sense that they represent more than $97 \%$ of the market capitalization of the liquid securities in the related market (Note 6). This study is based on Chinese A, B and $\mathrm{H}$ shares indices data which have been obtained from the Datastream. The interest rates for China (China interbank 3 month offered rate) and US (US treasury 3 month rate) are used as benchmark rates for the Chinese Yuan and US dollar equity returns respectively. All the data have monthly frequency and covers the period from January 1995 to June 2012.

\section{Estimation of the Sharpe Ratio and Testable Hypotheses}

\subsection{The Sharpe Ratio-Some Explanations}

As indicated by Sharpe (1994), there is some confusion relating to the definition and computation of the Sharpe ratio. Thus, estimation of the Sharpe ratio needs some issues to be clarified.

\subsubsection{Return Calculation}

The Sharpe ratio is dependent on the time over which the returns are calculated. Though returns for short periods can be annualized by using an appropriate multiplier they are unlikely to replace the true annual returns. Consequently, the end results are likely to have different statistical properties. For example, Lo (2002, p. 40) show that "a Sharpe ratio estimated from monthly data cannot be directly compared with one estimated from annual data". On the other side, if annual data is used for calculation of returns, this would reduce the number of observations significantly and the information content of results will be very poor. Sharpe (1994, p. 51) suggests that, "it is usually desirable to measure risks and returns using fairly short (e.g. monthly) periods. For purposes of standardization, it is then desirable to annualize the results." Considering both (Lo, 2002; Sharpe, 1994) arguments, all the returns in this study are measured over 12 month periods on a rolling basis from month to month. Rolling over monthly basis helps to generate a sufficient number of annual return observations and eliminates the possibility of any type of periodic bias in the results. 


\subsubsection{Time Period and Size Impact}

The Sharpe ratio is time and size variant. It changes with the time and number of observations included in the calculation of the Sharpe ratio. Thus, any conclusion based on a single Sharpe ratio is likely to be unreliable. Further, if Sharpe ratios are computed using the same number of observations, they can be used for comparing the performance of different assets. This study uses a series of rolling Sharpe ratios based on 36 observations (or 36 month/3 year time frame). Of course, critic may raise questions as to why not a larger number (e.g. 60) or a shorter number (e.g. 24) of observations. While there appears to be no clear cut answer for such questions, it is assumed that 36 observations is a reasonably fair number to start with and the estimated results can be subjected to robustness checks using relatively smaller and larger number of observations.

\subsubsection{Computation Confusion}

There appears to be some confusion in the literature in relation to the computation of the Sharpe ratio. Sharpe (1994) argues that, "Whether measured ex-ante or ex-post, it is essential that the Sharpe ratio be computed using the mean and standard deviation of a differential return." Thus, the Sharpe ratio computations in this study are based on the differential of stock returns and relevant interest rates. As mentioned in the data section, the interest rates selected for this study are the annualized yield on 3 month China interbank loan and 3 month US Treasury bill.

\subsection{Estimation of the Sharpe Ratio}

Consistent with above explanation (4.1.1), monthly-rolling annual returns (or 12 month rolling returns) are computed for four scenarios, namely A shares priced in Chinese Yuan, A shares priced in US dollar, H \& B shares priced in Chinese Yuan and $\mathrm{H} \& \mathrm{~B}$ shares priced in US dollar. For a typical index $\mathrm{i}$ and month $\mathrm{t}$, the annualized rate of return, $R_{i, t}$ is defined as:

$$
R_{i, t}=\frac{P_{i, t}-P_{i, t-12}}{P_{i, t-12}}
$$

where $P_{i, t}$ is the price (value) of index i at time t. Accordingly, there are four sets of returns based on the Chinese equity market indices for $A$ and $H \& B$ shares. These returns are symbolically (Note 7) represented as:

$$
R_{C N Y}^{A}, R_{U S D}^{A}, R_{C N Y}^{H+B} \text { and } R_{U S D}^{H+B}
$$

where ' $R$ ' stands for return, subscripts CNY and USD indicate the currency for prices of underlying stocks and superscripts $\mathrm{A}$ and $\mathrm{H}+\mathrm{B}$ are indicative of share type. Make a note that the Datastream indices for $\mathrm{A}$ shares are based on share prices in Yuan and H \& B share indices are based on US dollar prices. As such the Yuan /dollar exchange rate was applied to convert the returns from one currency to the other currency. Accordingly,

$$
R_{U S D}^{A}=\left(1+R_{C N Y}^{A}\right)(1+\Delta \mathrm{CNY})
$$

and,

$$
R_{C N Y}^{H+B}=\left(1+R_{U S D}^{H+B}\right)(1+\Delta \mathrm{USD}) \text { such that } \Delta \mathrm{CNY}+\Delta \mathrm{USD}+\Delta \mathrm{CNY} \times \Delta \mathrm{USD}=0
$$

Note that here $\triangle \mathrm{CNY}$ indicates corresponding period annual change in the exchange rate of CNY against the US dollar and vice versa $\triangle$ USD is the annual change in the exchange rate of USD against the Chinese Yuan.

For each series of above defined monthly-rolling annual returns, the Sharpe ratios are calculated using a 36 month (3 year) rolling framework. Based on equations 1 and 2, the Sharpe ratio calculations are consistent with explanations at 4.1.2 and 4.1.3. As a result, there are four sets of monthly-rolling 3-year the Sharpe ratios for the Chinese stock market. Consistent with the return notations at point 4 , the corresponding the Sharpe ratios (SR) are denoted as:

$$
S R_{C N Y}^{A}, S R_{U S D}^{A}, S R_{C N Y}^{H+B} \text { and } S R_{U S D}^{H+B}
$$

The empirical distributions of these Sharpe ratio series are used for testing the four hypotheses as explained in the following section. 


\subsection{Testable Hypotheses}

By definition, the Sharpe ratio represents a risk-adjusted measure of return. Thus, testing hypotheses based on distributions of the Sharpe ratio allows comparing the risk-return of the underlying stock price series. With a view to examining the first question from the domestic (Yuan) and foreign (US dollar) investors view point, the corresponding null and alternative hypotheses are specified as:

$$
\begin{array}{cc}
\mathrm{H} 1_{0}: S R_{C N Y}^{A}=S R_{C N Y}^{H+B} & \mathrm{H} 1_{1}: S R_{C N Y}^{A} \neq S R_{C N Y}^{H+B} \\
\mathrm{H} 2_{0}: S R_{U S D}^{A}=S R_{U S D}^{H+B} & \mathrm{H} 2_{1}: S R_{U S D}^{A} \neq S R_{U S D}^{H+B}
\end{array}
$$

Similarly, the second question can be viewed from the A shares and $H \& B$ shares perspective with the corresponding null and alternative hypotheses as:

$$
\begin{array}{ll}
\mathrm{H} 3_{0}: S R_{C N Y}^{A}=S R_{U S D}^{A} & \mathrm{H} 3_{1}: S R_{C N Y}^{A} \neq S R_{U S D}^{A} \\
\mathrm{H}_{0}: S R_{C N Y}^{H+B}=S R_{U S D}^{H+B} & \mathrm{H} 4_{1}: S R_{C N Y}^{H+B} \neq S R_{U S D}^{H+B}
\end{array}
$$

Results for mean and median equality tests relating the above hypotheses are available in Table 3. However, these tests have a limitation in the sense that they compare the overall distributions of the Sharpe ratios and fail to capture the chronological aspects. Thus a time series view and one to one comparison of corresponding the Sharpe ratios is provided by generating four Sharpe ratio differential (SRD) series (corresponding to four pairs of the Sharpe ratios discussed earlier) as under:

$$
\begin{array}{lc}
\text { SRD1: } S R_{C N Y}^{H+B}-S R_{C N Y}^{A} & \text { SRD2: } S R_{U S D}^{H+B}-S R_{U S D}^{A} \\
\text { SRD3: } S R_{U S D}^{A}-S R_{C N Y}^{A} & \text { SRD4: } S R_{U S D}^{H+B}-S R_{C N Y}^{H+B}
\end{array}
$$

These series are examined by conducting formal tests for mean and median and results are reported in Table 4 . Furthermore, graphic presentation of SRD1, SRD2, SRD3 and SRD4 (Figure 2) appear to provide interesting insights into the risk-return dynamics of $A$ and $\mathrm{H} \& B$ shares.

\section{Discussion of Results}

To begin with, let us have a look at the summary statistics of various variables used in this study (Table 2). The mean and median market returns for both $\mathrm{A}$ and $\mathrm{H}+\mathrm{B}$-shares measured in the US dollar are slightly higher than those of measured in the Chinese Yuan. This result appears to be the reflection of an appreciation of the Yuan against the US dollar over the study period. Relatively higher standard deviation of returns measured in the US dollar may indicate extra risk contributed by the exchange rate volatility.

Table 2. Summary statistics of selected variables used in the study

\begin{tabular}{cccccccccc}
\hline Variable & Mean & Median & Max & Min & Std. Dev. & Skewness & Kurtosis & JB test & Prob \\
\hline$\Delta$ CNY & 0.0170 & 0.0018 & 0.1107 & -0.0025 & 0.0266 & 1.7631 & 5.5256 & 156.77 & 0.0000 \\
$I N T_{C Y N}$ & 0.0379 & 0.0320 & 0.1066 & 0.0134 & 0.0161 & 1.7762 & 8.0672 & 319.14 & 0.0000 \\
$I N T_{U S D}$ & 0.0287 & 0.0293 & 0.0636 & 0.0001 & 0.0214 & -0.0380 & 1.3885 & 21.69 & 0.0000 \\
$R_{C N Y}^{A}$ & 0.1916 & 0.0222 & 2.4336 & -0.6920 & 0.5433 & 1.7449 & 6.2726 & 190.74 & 0.0000 \\
$R_{C N Y}^{H+B}$ & 0.1787 & 0.1353 & 1.4296 & -0.7767 & 0.4043 & 0.3927 & 3.2405 & 5.62 & 0.0601 \\
$R_{U S D}^{A}$ & 0.2124 & 0.0269 & 2.6250 & -0.6640 & 0.5632 & 1.8507 & 6.7374 & 230.57 & 0.0000 \\
$R_{U S D}^{H+B}$ & 0.1975 & 0.1431 & 1.5651 & -0.7765 & 0.4096 & 0.4149 & 3.3351 & 6.67 & 0.0356 \\
\hline
\end{tabular}

Note. a. $\triangle \mathrm{CNY}$ indicates annual change in the exchange rate of CNY (Chinese Yuan) against the US dollar.

b. $I N T_{C Y N}$ and $I N T_{U S D}$ are annual interest rates used as benchmark for risk free rates for China and the US respectively. These interest rates are China interbank 3 month offered rate and US treasury 3 month rate.

c. $R_{C N Y}^{A}$ stands for A shares index return when share prices are measured in the Chinese Yuan. Similarly other returns indicate the corresponding index and the underlying currency. 


\subsection{Comparing the Sharpe Ratio Distributions}

With a view to providing maximum information about the Sharpe ratio distributions, various graphic presentations such as histogram bars and polygons, kernel density graph and simple scatter diagrams were tried, but boxplots (BP) appear to capture more information and give a better picture of the underlying distribution. A boxplot (Note 8) summarizes the distribution of selected data by displaying the centre and spread of the data using some primary elements such as mean, median, first and third quartiles, near outliers and the far outlier. The box portion presents the middle $50 \%$ of the data with the first and third quartiles as lower and upper box boundaries. The median is shown with a line through the centre of the box, while the mean is indicated by dark dot.

Figure 1 presents pairwise boxplots corresponding to hypotheses (7a \&7b) specifications for the Chinese market index.

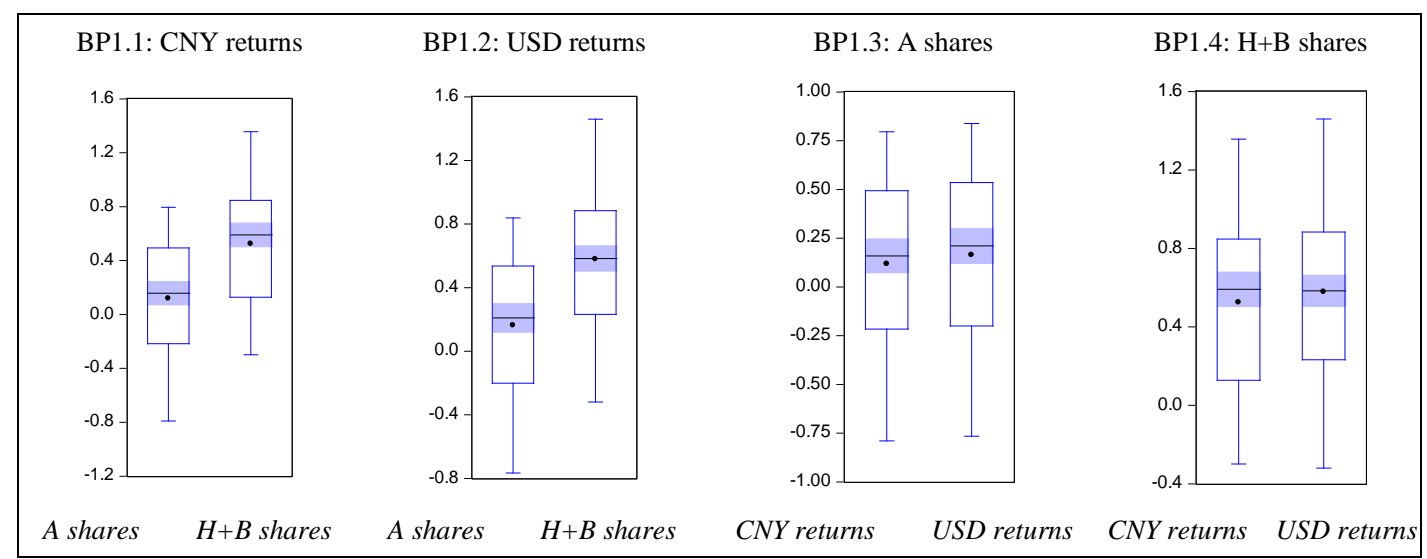

Figure 1. Boxplots (BP) of monthly-rolling 3-year the Sharpe ratios for the Chinese stock market

Notes. The box portion presents the middle half of the data. The line through the centre of the box represents the median and the dark dot is the mean. The lower and upper boundaries of the box are first and third quartiles respectively. CNY = Chinese Yuan; USD = US dollar.

A look at BP1.1 and BP1.2 sections of Figure 1 clearly reveals that H+B-shares offer a much better risk-adjusted return both from the domestic (CNY returns) and foreign (USD returns) investors view point. In fact, mean and median the Sharpe ratios for $\mathrm{H}+\mathrm{B}$-shares appear to be even above the third quartile of the Sharpe ratios for the A-shares. However, as indicated by BP1.3 and BP1.4 sections of Figure 1, there appears to be a little (if any) difference between the mean and median the Sharpe ratios from the domestic and foreign investors' perspective. In other words, the impact of exchange rate appears to be negligible. Any increased return from the appreciation of the Chinese Yuan against the US dollar appears to have been offset by an increased volatility arising from the exchange rate. Figure 1 observations are further supported by the formal test results presented in Table 3.

Table 3. Mean and median equality tests for the monthly-rolling 3-year the Sharpe ratios for the Chinese stock market

\begin{tabular}{|c|c|c|c|c|c|c|c|c|c|c|c|}
\hline \multicolumn{3}{|c|}{$H 1_{0}: S R_{C N Y}^{A}=S R_{C N Y}^{H+B}$} & \multicolumn{3}{|c|}{$H 2_{0}: S R_{U S D}^{A}=S R_{U S D}^{H+B}$} & \multicolumn{3}{|c|}{$H 3_{0}: S R_{C N Y}^{A}=S R_{U S D}^{A}$} & \multicolumn{3}{|c|}{$H 4_{0}: S R_{C N Y}^{H+B}=S R_{U S D}^{H+B}$} \\
\hline & mean & median & & mean & median & & mean & median & & mean & median \\
\hline$S R_{C N Y}^{A}$ & 0.1200 & 0.1719 & $S R_{U S D}^{A}$ & 0.1628 & 0.2133 & $S R_{C N Y}^{A}$ & 0.1200 & 0.1719 & $S R_{C N Y}^{H+B}$ & 0.5288 & 0.5997 \\
\hline$S R_{C N Y}^{H+B}$ & 0.5288 & 0.5997 & $S R_{U S D}^{H+B}$ & 0.5815 & 0.6019 & $S R_{U S D}^{A}$ & 0.1628 & 0.2133 & $S R_{U S D}^{H+B}$ & 0.5815 & 0.6019 \\
\hline test-stat & 67.84 & 18.66 & test-stat & 71.48 & 37.12 & test-stat & 0.8284 & 0.3067 & test-stat & 1.0273 & 0.0123 \\
\hline$p$-value & 0.0000 & 0.0000 & $p$-value & 0.0000 & 0.0000 & $p$-value & 0.3634 & 0.5797 & $p$-value & 0.3116 & 0.9118 \\
\hline
\end{tabular}

Note. Mean and median equality tests in this table are based on 163 observations of monthly-rolling the Sharpe ratios.

SR stands for the Sharpe ratio, subscripts CNY and USD indicate the currency in which stock returns are measured; superscripts A and H\&B are indicator of the share type. 
Mean and median values (Table 3) corresponding to hypotheses H1 \& H2 (specified at 7a) are hugely different and the p-values for all the tests are nearly zero. Thus the nulls of equality of the mean and median are strongly rejected. In case of hypotheses H1 \& H2, the mean and median Sharpe ratios for the H+B-shares are about three times higher than that of the A-shares. However, test results for the hypotheses $\mathrm{H} 3$ \& $\mathrm{H} 4$ (specified at $7 \mathrm{~b}$ ) do not support the rejection of equality of the mean and median even at the $10 \%$ level.

\subsection{One to One and Timeline Comparison of the Sharpe Ratios}

As mentioned earlier, the tests focused on the Sharpe ratio distributions cannot reveal the 'timeline' aspects of the risk-return characteristics of the Chinese stocks. Thus examining the Sharpe ratio differential (SRD) series is important. Formal hypotheses tests (mean $=0$, median $=0$; Table 4 ) for SRD series indicate that the mean and median for all the four SRD series are statistically significantly different from zero and all are positive. These results (relating SRD1 and SRD2) suggest that during the study period, on average, risk-adjusted return from $\mathrm{H}+\mathrm{B}$-shares exceeded that of A-shares both in terms of domestic and foreign currencies. On the other side, results for SRD3 and SRD4 indicate that (irrespective of share type) on average foreign (US dollar) investors had some relative advantage over domestic investors due to exchange rate changes. Furthermore, the mean and median values in Table 4 clearly indicate that exchange rate advantage for foreign investors is quite small as compared to advantage from investing in $\mathrm{H}$ and $\mathrm{B}$-shares relative to investing in $\mathrm{A}$-shares.

Table 4. An analysis of the Sharpe ratio differentials (SDR) series

\begin{tabular}{|c|c|c|c|c|c|c|c|c|}
\hline SRD series & \multicolumn{2}{|c|}{ SRDI } & \multicolumn{2}{|c|}{$S R D 2$} & \multicolumn{2}{|c|}{$S R D 3$} & \multicolumn{2}{|c|}{ SRD4 } \\
\hline \multicolumn{9}{|l|}{ Test of Hypothesis: Mean $=0.0000$} \\
\hline Sample Mean & 0.4087 & & 0.4188 & & 0.0427 & & 0.0528 & \\
\hline Sample Std. Deviation & 0.7012 & & 0.6816 & & 0.0678 & & 0.0643 & \\
\hline Test Method & Value & Prob & Value & Prob & Value & Prob & Value & Prob \\
\hline t-statistic & 7.4416 & 0.0000 & 7.8441 & 0.0000 & 8.0494 & 0.0000 & 10.4749 & 0.0000 \\
\hline \multicolumn{9}{|c|}{ Test of Hypothesis: Median $=0.0000$} \\
\hline Sample Median & 0.2968 & & 0.3597 & & 0.0547 & & 0.0413 & \\
\hline Test Method & Value & Prob & Value & Prob & Value & Prob & Value & Prob \\
\hline Sign (exact binomial) & 114 & 0.0000 & 118 & 0.0000 & 112 & 0.0000 & 123 & 0.0000 \\
\hline Sign (normal approximation) & 5.0129 & 0.0000 & 5.6395 & 0.0000 & 4.6996 & 0.0000 & 6.4227 & 0.0000 \\
\hline Wilcoxon signed rank & 6.3421 & 0.0000 & 6.7547 & 0.0000 & 7.0662 & 0.0000 & 8.1846 & 0.0000 \\
\hline van der Waerden (normal scores) & 6.5107 & 0.0000 & 6.8401 & 0.0000 & 7.1902 & 0.0000 & 8.0606 & 0.0000 \\
\hline \multicolumn{9}{|l|}{ Median Test Summary } \\
\hline Category & Count & Mean Rank & Count & Mean Rank & Count & Mean Rank & Count & Mean Rank \\
\hline Obs $>0.0000$ & 114 & 92.20 & 118 & 91.19 & 112 & 97.75 & 123 & 94.50 \\
\hline Obs $<0.0000$ & 49 & 58.27 & 45 & 57.91 & 51 & 47.41 & 40 & 43.58 \\
\hline Obs $=0.0000$ & 0 & & 0 & & 0 & & 0 & \\
\hline Total Observations & 163 & & 163 & & 163 & & 163 & \\
\hline
\end{tabular}

Note. SDR series are defined as: $S R D 1=S R_{C N Y}^{H+B}-S R_{C N Y}^{A} ; S R D 2=S R_{U S D}^{H+B}-S R_{U S D}^{A} ; S R D 3=S R_{U S D}^{A}-S R_{C N Y}^{A} ;$ and $S R D 4=S R_{U S D}^{H+B}-S R_{C N Y}^{H+B}$

However, the summary of median tests (Table 4) and graphs of SRD series (Figure 2) appears to suggest that generalisation of above results need some caution. The median test summary indicates that $25 \%$ to $31 \%$ of the 163 the Sharpe ratio values violated the above conclusions. In other words, there is at least $25 \%$ probability that the risk adjusted performance of A shares may be better than the $\mathrm{H} \& \mathrm{~B}$ shares. Interestingly, during the initial periods (as indicated by sections of graphs below the dotted lines, Figure 2) A shares performed better than $\mathrm{H} \&$ $\mathrm{B}$ shares and exchange rate favored the domestic investors. This finding may suggest that the introduction of different class of shares for foreign investors by the Chinese authorities may indirectly be a strategy to provide 
protection to the domestic investors during the initial stage of stock market development in China. Moreover, this type of protection may be helpful in generating positive investor sentiment in the local population.

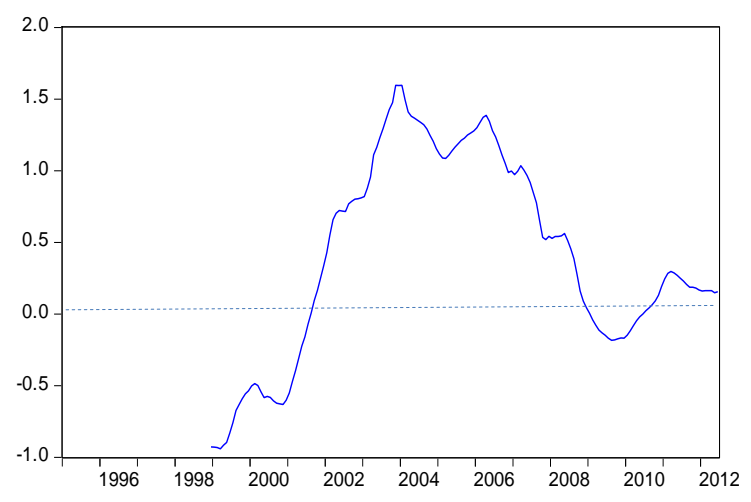

Figure 2.1. Graph of SRD1 $=S R_{C N Y}^{H+B}-S R_{C N Y}^{A}$

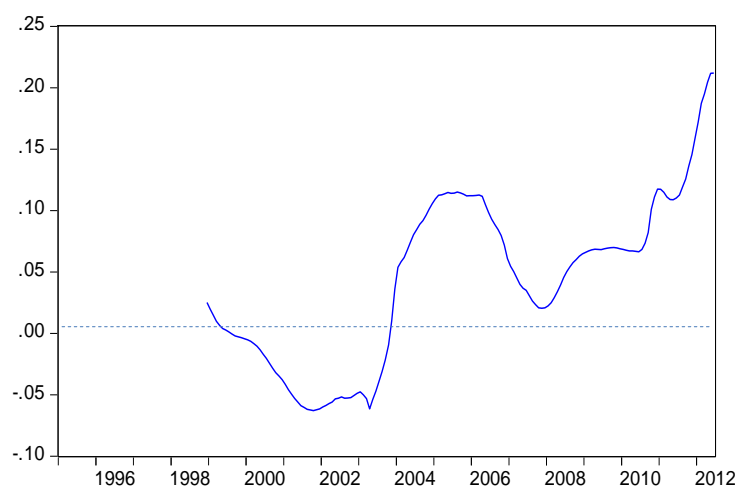

Figure 2.3. Graph of SRD3 $=S R_{U S D}^{A}-S R_{C N Y}^{A}$

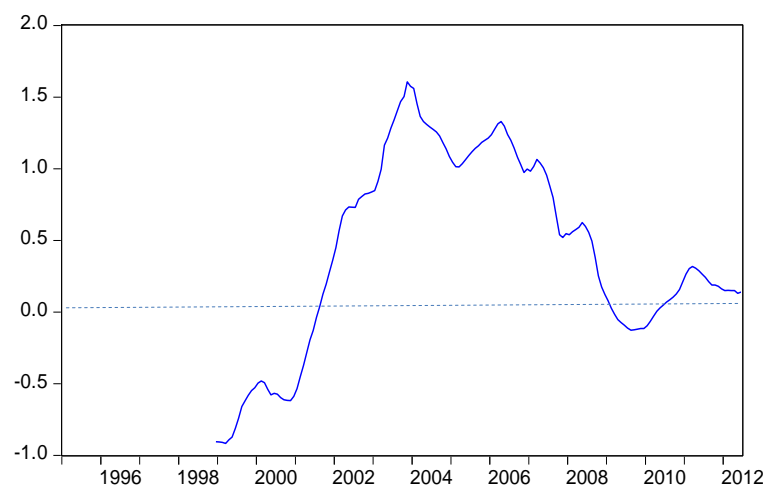

Figure 2.2. Graph of SRD2 $=S R_{U S D}^{H+B}-S R_{U S D}^{A}$

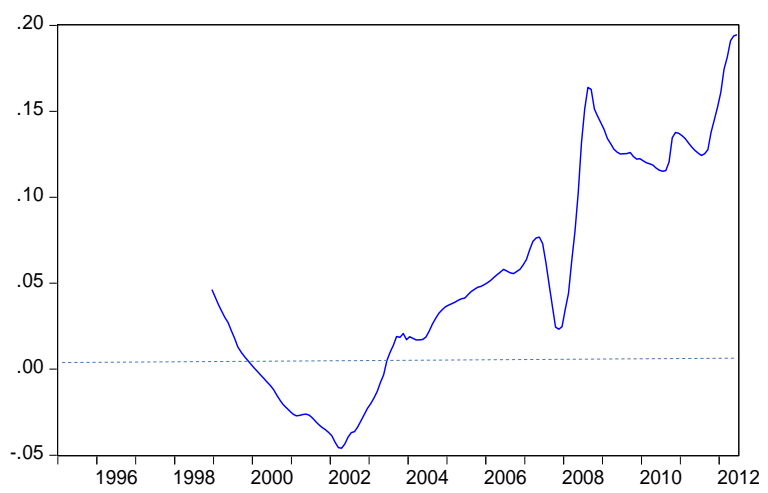

Figure 2.4. Graph of SRD4 $=S R_{U S D}^{H+B}-S R_{C N Y}^{H+B}$

Figure 2. A timeline view of the Sharpe ratio differentials for the Chinese market

Generally, an initial success in the stock markets is likely to make the investors more investment enthusiastic and risk taker. Over time this can result in over shooting of stock prices translating into lower risk adjusted returns. Thus, it is not surprising that the domestic Chinese investors may have pushed the prices of A shares beyond equilibrium level against the H \& B shares. Perhaps the reversal trend in SRD1 and SRD2 graphs (Figure 2.1 and Figure 2.2) during the second half of study period may be a reflection of policy measures such as opening of $B$ shares to domestic investors, QFIIs and QDIIs schemes enabling foreign and domestic financial institutions to cross each other's investment territories. The graphic fluctuations (graphs of SRD1 and SRD2) above and below the dotted line during the later periods of the study appears to indicate that the gap between the performances of $\mathrm{A}$, and $\mathrm{H} \& \mathrm{~B}$ shares is narrowing and may be searching for equilibrium. As regarding the exchange rate impact, it appears to offer some incentive to foreign investors for investing in China.

\subsection{Robustness of Results}

As indicated earlier, the Sharpe ratio has a drawback that its value varies with the number of return observations included in the calculation. Presumably, a change in the number of return observations can impact on the Sharpe ratio values, but it does not mean that the comparative characteristics of the Sharpe ratio distributions will change. As the Sharpe ratios used in this study are based on 36 return observations, the impact of 24 and 60 return observations on the results were tested. While the values of the Sharpe ratios change with the number of observations, but they do not change the findings stated in previous sections. Thus, the findings of this study appear to be independent of the number of return observations used in the calculation of the Sharpe ratios. 


\section{Summary and Conclusions}

The Chinese stock market has many special features compared to other stock markets around the world. For example, Chinese stocks are divided into different classes like A shares, B shares and $\mathrm{H}$ shares and they trade in different currencies. Moreover, there are various types of restrictions which apply to trading of shares by the Chinese and foreign investors. In general, A shares are priced in the Chinese Yuan and trade in the domestic environment. On the other hand, $\mathrm{H}$ and $\mathrm{B}$ shares (grouped as $\mathrm{H} \& \mathrm{~B}$ shares) are mostly dominated by $\mathrm{H}$ shares as explained in footnote (6) are priced in foreign currencies and aimed at sourcing foreign capital.

Our study examines the risk-return characteristics of A shares (domestic perspective) versus H\&B shares (foreign perspective). Our findings suggest that on average, $\mathrm{H} \& \mathrm{~B}$ shares index generated a better risk-adjusted return in comparison to A shares over the study period (1995-2012) irrespective of whether the returns were measured in the Chinese Yuan (domestic perspective) or in the US dollar (foreign perspective). Further, our results based on Sharpe ratios indicate that the relative advantage from investing in $H \& B$ shares index may be nearing the end. This finding may be attributed to the scheme which allowed domestic and foreign investors to cross each other's territories specified when the Chinese market was originally opened up to foreign investors. Second, the evidence suggests there is some exchange rate advantage for foreign investors, even though it is negligible. This finding may indicate that any marginal benefit generated by a slight (average annual) appreciation of the Yuan against the dollar is offset by an increase in the volatility of returns measured in the US dollar.

\section{Acknowledgements}

Authors gratefully acknowledge the comments and advice from anonymous reviewer and the editor of Internal Business Research. We are grateful to the Brooklyn College's School of Business, and King Abdulaziz University for providing research support. Authors remain responsible for any errors.

\section{References}

Bailey, W. (1994). Risk and return on China's new stock markets: Some preliminary evidence. Pacific-Basin Finance Journal, 2, 243-260. http://dx.doi.org/10.1016/0927-538X(94)90019-1

Beltratti, A., Bortolotti, B., \& Caccavaio, M. (2012). The stock market reaction to the 2005 split share structure reform in China. Pacific-Basin Finance Journal, 20, 543-560. http://dx.doi.org/10.1016/j.pacfin.2012.01.004

Berkman, H., Cole, R. A., \& Fu, L. J. (2010). Political connections and minority-shareholder protection: Evidence from securities-market regulation in China. Journal of Financial and Quantitative Analysis, 45, 1391-1417. http://dx.doi.org/10.1017/S0022109010000608

Bohl, M. T., Schuppli, M., \& Siklos, P. L. (2010). Stock return seasonalities and investor structure: Evidence from China's B-share markets. China Economic Review, 21, 190-201. http://dx.doi.org/10.1016/j.chieco.2009.12.004

Chan, H. K., Lin, K. Z., \& Zhang, F. (2007). On the association between changes in corporate ownership and changes in auditor quality in a transitional economy. Journal of International Accounting Research, 6, 19-36. http://dx.doi.org/10.2308/jiar.2007.6.1.19

Chen, C., Jin, Q., \& Yuan, H. (2011). Agency problems and liquidity premium: Evidence from China's stock ownership reform. International Review of Financial Analysis, 20, 76-87. http://dx.doi.org/10.1016/j.irfa.2011.02.007

Chen, Q., Chen, X., Schipper, K., Xu, Y., \& Xue, J. (2012). The sensitivity of corporate cash holdings to corporate governance. Review of Financial Studies, 25, 3610-3644. http://dx.doi.org/10.1093/rfs/hhs099

Chen, Z., Jiang, H., Li, D., \& Sim, A. B. (2010). Regulation change and volatility spillovers: Evidence from China's stock markets. Emerging Markets Finance \& Trade, 46, 140-157. http://dx.doi.org/10.2753/REE1540-496X460609

Chinese Securities Regulatory Commission (CSRC). (2008). China capital markets development report-2008. Retrieved from http://www.csrc.gov.cn/pub/csrc_en/Informations/publication/

Chinese Securities Regulatory Commission (CSRC). (2011). Annual report. Retrieved on December 20, 2012 from http://www.csrc.gov.cn/pub/csrc_en/about/annua

Darrat, A. F., Gilley, O., Wu, Y., \& Zhong, M. (2010). On the Chinese B-share price discount puzzle: Some new evidence. Journal of Business Research, 63, 895-902. http://dx.doi.org/10.1016/j.jbusres.2010.02.015 
Firth, M., Fung, P. M. Y., \& Rui, O. M. (2007). Ownership, two-tier board structure, and the informativeness of earnings-Evidence from China. Journal of Accounting \& Public Policy, 26, 463-496. http://dx.doi.org/10.1016/j.jaccpubpol.2007.05.004

Green, W., Morris, R. D., \& Tang, H. (2010). The split equity reform and corporate financial transparency in China. Accounting Research Journal, 23, 20-48. http://dx.doi.org/10.1108/10309611011060515

Guo, T. (2007). Should the different share classes of Chinese companies trade at par when there is no capital flow restriction? AIMA (Alternative Investment Management Association) Journal, 71. Retrieved from $\mathrm{http}: / / \mathrm{www}$.aima.org/en/knowledge_centre/education/aima-journal/past-articles

Hou, W., Kuo, J. M., \& Lee, E. (2012). The impact of state ownership on share price informativeness: The case of the split share structure reform in China. British Accounting Review, 44, 248-261. http://dx.doi.org/10.1016/j.bar.2012.09.003

Johansson, A. C. (2009). An analysis of dynamic risk in the greater China equity markets. Journal of Chinese Economic and Business Studies, 7(3), 299-320. http://dx.doi.org/10.1080/14765280903073165

Lee, J., \& Poon, J. (2005). Convergence of A-share and H-share prices. SFC research paper 19. Retrieved from http://www.sfc.hk/web/EN/regulatory-functions/market-infrastructure-and-trading/market-infrastructure/res earch-papers.html

Li, K., Wang, T., Cheung, Y. L., \& Jiang, P. (2011). Privatization and risk sharing: Evidence from the split share structure reform in China. Review of Financial Studies, 24, 2499-2525. http://dx.doi.org/10.1093/rfs/hhr025

Li, Y., Yan, D., \& Gerco, J. (2006). Market segmentation and price differentials between A-shares and H-shares in the Chinese stock markets. Journal of Multinational Financial Management, 16, 232-248. http://dx.doi.org/10.1016/j.mulfin.2005.07.003

Lo, A. W. (2002). The statistics of the Sharpe ratio. Financial Analysts Journal, 58(4), 36-52. http://dx.doi.org/10.2469/faj.v58.n4.2453

Seiler, M. J., Harrison, D. M., Vliet, P. V., \& Yeung, K. C. (2005). Return characteristics of state-owned and non-state-owned Chinese A shares. Financial Review, 40, 533-548. http://dx.doi.org/10.1111/j.1540-6288.2005.00123.x

Sharpe, W. F. (1966). Mutual funds performance. Journal of Business, January, 119-138. http://dx.doi.org/10.1086/294846

Sharpe, W. F. (1994). The Sharpe ratio. Journal of Portfolio Management, 21, 49-58. http://dx.doi.org/10.3905/jpm.1994.409501

Shum, W. C., \& Tang, G. (2010). Risk-return characteristics: Comparison of China's stock market and three other emerging markets. The Chinese Economy, 43(5), 15-31. http://dx.doi.org/10.2753/CES1097-1475430502

Sun, Q., \& Tong, W. H. S. (2000). The effect of market segmentation on stock prices: The China syndrome. Journal of Banking and Finance, 24, 1875-1902. http://dx.doi.org/10.1016/S0378-4266(99)00121-1

Tan, L., Chiang, T. C., Mason, J. R., \& Nelling, E. (2008). Herding behavior in Chinese stock markets: An examination of A and B-shares. Pacific-Basin Finance Journal, 16, 61-77. http://dx.doi.org/10.1016/j.pacfin.2007.04.004

Thomson Reuters. (2012). Datastream global equity indices-Index hierarchy: Sector, country and regional codes-July $2012 . \quad$ Retrieved from http://extranet.datastream.com/data/Equity\%20indices/DSGlobalEquityIndices.htm

Tong, W. H. S., \& Yu, W. W. (2012). A corporate governance explanation of the A-B share discount in China. Journal of International Money \& Finance, 31, 125-147. http://dx.doi.org/10.1016/j.jimonfin.2011.09.006

Wang, S. S., \& Jiang, L. (2004). Location of trade, ownership restrictions, and market illiquidity: Examining Chinese A- and H-shares. Journal of Banking and Finance, 28, 1273-1297. http://dx.doi.org/10.1016/S0378-4266(03)00119-5

Yin-Hua, Y., Tsun-siou, L., \& Jen-Fu, P. (2002). Stock returns and volatility under market segmentation: The case of Chinese A and B-shares. Review of Quantitative Finance and Accounting, 18, 239-257. http://dx.doi.org/10.1023/A:1015388201113

Zou, H., \& Adams, M. B. (2008). Corporate ownership, equity risk and returns in the People's Republic of China. 
Journal of International Business Studies, 39, 1149-1168. http://dx.doi.org/10.1057/palgrave.jibs.8400394

\section{Notes}

Note 1. Chinese stocks indicate shares issued by the companies incorporated/domiciled in the People's Republic of China. These companies do not include the companies incorporated in Hong Kong and other administrative territories outside the mainland China.

Note 2. More features of A-, B- and H-shares are discussed under section 2.1 (An overview of the Chinese market).

Note 3. CSRC publication: China Capital Markets Development Report-2008.

Note 4. Available at CSRC website: www.csrc.gov.cn/pub/csrc_en/ (accessed December 2012)

Note 5. As explained in the Thomson Reuters (2012) Datastream Global Equity Indices user guide (Issue 5, page 34), the China A index is comprised of class A-shares of mainland Chinese companies traded on the Shanghai and Shenzen exchanges and which are investable only by Chinese nationals. The China (H\&B) index is comprised of class $\mathrm{H}$ shares of mainland Chinese companies traded on the Hong Kong exchange and which are investable by non-nationals and class B-shares traded in China by non-nationals. Many major Chinese companies issue several classes of shares and therefore have constituents in both indices.

Note 6. As on 10 July 2012 (date of data download), the China A index represented 400 companies. The H\&B index represented 50 companies containing $47 \mathrm{H}$ shares and $3 \mathrm{~B}$ shares. As such $\mathrm{H} \& \mathrm{~B}$ is dominated by $\mathrm{H}$ shares index.

Note 7. As in equation 3, subscripts ' $\mathrm{i}, \mathrm{t}$ ' can be added to the symbols (point 4) to represent index i and period t, but I feel it will overcrowd the symbols without adding any value.

Note 8. See more details in Eviews 7 user's guide, pp. 509-610.

\section{Copyrights}

Copyright for this article is retained by the author(s), with first publication rights granted to the journal.

This is an open-access article distributed under the terms and conditions of the Creative Commons Attribution license (http://creativecommons.org/licenses/by/3.0/). 